The Decline and Rise of Neighbourhoods: the importance of neighbourhood governance

\author{
Peter Somerville \\ Department of Policy Studies \\ University of Lincoln \\ Brayford Pool \\ Lincoln LN6 7TS \\ Tel: +44 1522886267 \\ Email: psomerville@lincoln.ac.uk \\ Ronald van Kempen \\ Urban and Regional Research Centre Utrecht \\ Faculty of Geosciences \\ Utrecht University \\ PO Box 80.115 \\ 3508 TC Utrecht \\ The Netherlands \\ Tel: +31302532243 \\ Email: r.vanKempen@geo.uu.nl \\ Ellen van Beckhoven \\ Municipality of Utrecht \\ Housing Department \\ Gebouw 2, kamer 427, \\ Bezoekadres Rachmaninoffplantsoen 61 \\ PO Box 8406 \\ 3503 RK Utrecht \\ The Netherlands \\ Tel: +31 302864405 \\ Email: e.van.beckhoven@utrecht.nl
}




\section{The Decline and Rise of Neighbourhoods: the importance of neighbourhood governance}

\section{Abstract}

There is a substantial literature on the explanation of neighbourhood change. Most of this literature concentrates on identifying factors and developments behind processes of decline. This paper reviews the literature, focusing on the identification of patterns of neighbourhood change, and argues that the concept of neighbourhood governance is a missing link in attempts to explain these patterns. Including neighbourhood governance in the explanations of neighbourhood change and decline will produce better explanatory models and, finally, a better view about what is actually steering neighbourhood change.

Key words: neighbourhood, governance, neighbourhood change, neighbourhood decline

\section{Introduction}

Numerous studies of neighbourhood change, and of neighbourhood decline in particular, have been published in the last century. It has been adequately described in most of these studies that problems confronting particular neighbourhoods never stand alone but are connected with one another and in most cases also with developments outside the area (see, e.g., Hall, 1997; Marcuse \& Van Kempen, 2000; Megbolugbe et al., 1996; Murie et al., 2003; Van Kempen, 2002). Knowledge of how to handle these problems has been extended in the last two decades, by combining several ideas from traditional approaches and by developing comprehensive models of neighbourhood 
change. ${ }^{1}$ Despite all these efforts, however, one major field of activity appears to have received insufficient attention in the models, namely, that of neighbourhood governance.

We start, therefore, with an analysis of what is meant by neighbourhood governance. We then move on to a discussion of ecological and behavioural approaches to neighbourhood change, drawing mainly from sociological and criminological literature. We develop the argument that governance tends to be a silent factor in such accounts, mediated largely through an emphasis on social institutions and structures. We then focus on more structural approaches, varying according to their emphases on economic, social or spatial dimensions. Here we highlight the absence of a theoretically explicit account of neighbourhood governance. Finally, through a discussion of the value and limitations of structural approaches, we foreground the concept of neighbourhood governance as a means to improve our understanding of neighbourhood dynamics. We conclude with some comments about how horizontally developed neighbourhood governance structures might play a role in wider programmes of democratic integration and inclusion.

\section{The meaning of neighbourhood governance}

In recent years, especially in England, there has been an increasing interest in the neighbourhood as a site or space for urban and social activity, and particularly for governance activity (Taylor, 2000; Kearns and Parkinson, 2001; Sullivan, 2001, 2002; Whitehead, 2003; ODPM, 2005; Purdue, 2005; Robinson et al., 2005; Hilder, 2006; Keil, 2006; White et al., 2006; Smith et al., 2007). A recent issue of Urban Studies,

\footnotetext{
${ }^{1}$ In addition, there has been a burgeoning literature on community participation designed to address these problems but, as shown below, this has not necessarily involved participation in governance and, where it has, the governance in which such participation occurs has not necessarily been neighbourhood governance.
} 
however, suggested that 'the neighbourhood is at best a chaotic concept' (Kennett and Forrest, 2006: 715), with its use, meaning and role varying enormously across European societies. Galster (2001), on the other hand, suggests that the meaning of neighbourhood is clear enough, being tied to the value of its attributes for those located in a defined territory: that is, where a group of people all derive value from the same attributes of the same area, we can call that area a neighbourhood. The apparently chaotic character of 'neighbourhood', then, could be due to confusion about its precise scale of operations, i.e. where its territory is not clearly defined or is contested (Somerville, 2009).

The literature on governance in general, and on urban governance in particular, has grown immensely in the past two decades. It is not our intention to review this literature here, but it is important to come to a definition. In essence governance is about working together, about the cooperation between different (kinds of) stakeholders, such as national and local government, residents and resident organisations, housing associations and private partners such as developers and insurance companies (see, e.g., Bailey et al., 1995; Clark \& Newman, 1997; Dekker \& Van Kempen, 2004; Imrie \& Raco, 1999; Kooiman, 1993; Rhodes, 1996; Rhodes, 1997; Elander, 2002; Stone, 1989). Governance can be understood, following Le Galès (1998: 496), as a double capacity, to shape collectivities (interests, groups, organisations, territories) and to represent them in different arenas. Kooiman (2005) has distinguished three modes of governance: hierarchical governance, selfgovernance and co-governance. Hierarchical governance is 'top-down' governance in which a central 'governator' dominates the shaping and representing of a collectivity. Self-governance is 'bottom-up' governance in which a collectivity is able to shape and represent itself. Co-governance is then where a collectivity works co-operatively 
with other collectivities, in a process of mutual shaping and mutual representation. We have found this typology useful for making sense of neighbourhood governance.

Using Le Galès' definition, neighbourhood governance can be conceptualised in terms of the capacity to shape the attributes of a neighbourhood (as defined by Galster) and to represent that neighbourhood, at least partially, in interactions with others. Such shaping can be conducted in an unplanned way, through interactions between elements of the neighbourhood (not just among residents or those with a 'stake' in the neighbourhood but also between residents and features of the neighbourhood environment), or in a planned way, through organisations and institutions set up specifically for this purpose. ${ }^{2}$ These individuals and organisations also provide the means by which the neighbourhood is represented in other arenas. We hypothesise that the decisions and actions of such organisations play a key role in neighbourhood change and we will make clear that the importance of such decisions and actions is underestimated, or even not recognised, in many important theoretical models of neighbourhood change and decline. We reject, however, the conflation of neighbourhood governance with neighbourhood management or with 'arrangements for collective decision-making and/or public service delivery at the sub-local authority level' (Lowndes and Sullivan, 2008, cited in Smith et al, 2007: 2). ${ }^{3}$

Following Kooiman (2005), neighbourhood governance can be hierarchical and even more or less forced, where the shaping and representing of the neighbourhood is conducted, for example, by national or local government based outside the neighbourhood, with little scope for alternative shaping or representation

\footnotetext{
${ }^{2}$ Recent research on neighbourhood governance in Britain (Somerville \& Haines, 2008) indicates a huge variety, not only of neighbourhood governance bodies themselves (e.g. parish and town councils, neighbourhood management bodies, community-based housing organisations and community associations and forums) but also of activities performed by these different bodies.

${ }^{3}$ Neighbourhood management involves shaping but not necessarily representing of the neighbourhood. The definition by Lowndes and Sullivan, on the other hand, includes forms of representation but not necessarily of the neighbourhood.
} 
from local residents. Here the governance institution is typically a governmental body acting as an instrument or 'site' (Smith et al., 2007) for the implementation of government policies within the neighbourhood. Or it can be self-governance, where the shaping and representing of the neighbourhood is carried out by the residents themselves. Here governance institutions are typically community or residents' associations or forums based in the neighbourhood. Or it can be co-governance, where the shaping and representation of the neighbourhood is done jointly by governmental and non-governmental bodies, for example, in forms of neighbourhood partnership.

\section{Ecological and behavioural approaches to neighbourhood change}

Evidence from a wide variety of sources, and over several decades, has supported the thesis that the key causes of neighbourhood change are socio-economic (particularly, unemployment and poverty), with their effects being mediated by housing market processes and social relations within the neighbourhood itself (see, for example, Molotch, 1976; Pahl, 1975, 1977; Lipsky, 1980; Taub et al., 1984; Schuerman \& Kobrin, 1986; Evans, 1998; Walklate \& Evans, 1999; Hancock, 2001; Bottoms \& Wiles, 2002; Lupton, 2004). This section and the following one review the main attempts to understand neighbourhood change that have been developed over the years.

The first of these attempts was probably the human ecology approach of the Chicago School in the 1920s with their identification of filtering processes resulting from an ageing housing supply (see, for example, Burgess, 1925; Hoyt, 1933; and later Birch, 1971). Since the Second World War, evidence for such long-term processes of change has been found in the public housing sectors of many countries, according to which higher-income households have tended to move out, and been 
replaced by lower-income households, resulting in a decline in the status of public housing neighbourhoods (Cole \& Furbey, 1994). Such processes of succession, along with processes of invasion and filtering, can still be identified in numerous neighbourhoods throughout the world (see, e.g., Power, 1997; Murie et al., 2003; Hall et al., 2003, for an overview of the developments in London and Birmingham; Aalbers et al., 2003, for an overview of the developments in Amsterdam and Utrecht; Turkington et al., 2004).

The human ecology approach, however, was soon criticised as being oversimplified and over-deterministic (see, for example, Firey, 1947; and later, Ahlbrandt \& Brophy, 1975; Ahlbrandt \& Cunningham, 1979). For the purpose of this paper, we can add that attention to neighbourhood governance was lacking in these studies.

A number of the early critics of the Chicago School advocated a focus on a more behavioural approach, in which neighbourhood decline (and perhaps neighbourhood change generally) is not seen as an inevitable process but can be offset by people's conscious actions, and specifically also by the strength of social networks within neighbourhoods (see, e.g., Ahlbrandt \& Cunningham, 1979; Varady, 1986; Temkin \& Rohe, 1996; 1998). Implicitly agreeing with this, Bottoms and colleagues (1992: 123), for example, suggested that the housing market 'interacts with a range of other aspects of social life to create the relevant social effects', for example, social networks, socialisation processes, social control agencies, reputations and labels, economic development, and the physical form of the locality. The web of interaction is complex, but Bottoms and his co-workers believe that it is possible to identify certain patterns of change in particular neighbourhoods.

Initial evidence for the existence of such patterns of neighbourhood change was provided by Baldwin \& Bottoms (1976) in their studies of Sheffield. Their first 
study identified housing allocation processes as a key factor in explaining why two similar interwar council housing estates, with similar social class and gender composition, and relatively well-settled populations, had such different offending rates (three times as high in one as in the other). Although both estates began as 'good', crime-free areas in the 1920s, one of them 'tipped' sometime in the 1940s for reasons unknown and, once tipped, the council's allocation rules had the unintended effect of maintaining the difference between the two areas. When their study was replicated in 1988, however, the offence rates on the two estates were similar. The reason for this was that the worse estate improved, as modernisation and decanting broke up the criminal sub-culture that had long existed on part of the estate, the child density was reduced, the local school improved, and a crime reduction initiative (strengthening residents' organisational capacity) had a long-term impact; while the better estate deteriorated, through rehousing slum tenants and homeless families (Bottoms et al., 1989; Bottoms et al., 1992; Bottoms \& Wiles, 2002: 635-6). This example illustrates how long-term processes of neighbourhood decline and rise can result from a complex combination of ecological (e.g. population moves), institutional (e.g. management rules) and sub-cultural (e.g. offending cultures) factors.

The importance of this study for our argument in this paper is that the management rules look like manifestations of neighbourhood governance, in the sense that they are rules about how housing should be allocated in a neighbourhood. Interestingly, however, the purpose of these rules is not to shape the attributes of the neighbourhood in which they apply, let alone represent that neighbourhood to others. Rather, the purpose of these rules is to ensure the fair distribution of housing on a 
municipal scale - there are no rules specific to the neighbourhood and no representation of the neighbourhood at the municipal level.

In their research in Chicago, Taub and colleagues (1984) similarly concluded that changes in neighbourhood status could be explained in terms of a behavioural mix of ecological, institutional and sub-cultural or individual factors. The factors involved, however, were slightly different from those identified by Bottoms and colleagues. The ecological factors were the potential employment base, the pressure on the housing market, the age and quality of the housing stock, and the nature of the local amenities. The institutional factors were corporate and institutional decisions, for example, by banks, insurance companies and universities. And the individual or sub-cultural factors were decisions to move home, for example, because of dissatisfaction with the area or concerns about crime or fears of abandonment. In this case, the institutions involved were primarily private rather than public sector, reflecting perhaps the institutional and political differences between the UK and the US. As with Baldwin and Bottoms, however, the researchers did not explicitly identify any particular capacity (whether ecological, institutional or sub-cultural) to shape the attributes of a neighbourhood or to represent the neighbourhood to others, i.e. the issue of neighbourhood governance (or the lack of it) was not addressed. ${ }^{4}$

Taub et al (1984) also noticed something else. They identified the possibility that different neighbourhood residents respond differently to similar neighbourhood attributes (see also Temkin \& Rohe, 1996). The effect of this difference is to make

\footnotetext{
${ }^{4}$ For another example, see Schuerman \& Kobrin (1986). Here, changes in neighbourhoods from lowcrime to high-crime status are also explained in terms of a combination of ecological (demographic change, such as population decline, an increase in the proportion of unrelated residents, and an increase in residential mobility), institutional (shifts in land use, such as an increase in renting or in apartment dwellings) and sub-cultural (changes in the socio-economic status of residents, such as more unskilled and more unemployed, and in explicit subculture variables such as an increase in black and minority ethnic households) factors. However, this is little different from an ecological approach, because the institutional and sub-cultural factors are themselves presented as quasi-ecological, i.e. as involving succession, invasion, filtering, etc.
} 
patterns of neighbourhood change potentially far more complex. The researchers noted that the impact of disorder, for example, depends, in part, on the level of tolerance community members feel towards that disorder, with different members having more or less tolerance or more or less capacity to move away. Similarly, a longitudinal study of neighbourhoods in Baltimore (Taylor, 2001) found that disorder or incivilities were not as consistently important as other features of the neighbourhood, particularly its social status. ${ }^{5}$ So it appears that certain features of the neighbourhood environment (such as the prevalence of crime and disorder) can cause neighbourhood decline, while other features (to do with residents' capacity and amenities) can act against this. These studies suggest a certain 'collective efficacy' (Sampson et al, 1997) or resilience that residents exhibit in the face of neighbourhood decline, but they fall short of explicitly identifying forms of resident shaping or representation of the neighbourhood that might embody or institutionalise such efficacy or resilience. The possibility that 'voice' as well as 'exit' might determine neighbourhood change is raised for the first time in these studies, but the forms of expression of that voice remain to be explored.

Another example of a behavioural approach is Prak \& Priemus (1986). From their studies of social rented housing in Europe, and in the Netherlands in particular, they developed a model of neighbourhood change based on three self-reinforcing or mutually reinforcing spirals of decline: social, economic and technical. In this model, relatively small changes in one factor can trigger more far-reaching consequences across a range of factor types. Social decline concerns changes that take place within the tenant population. When the attractiveness of an estate decreases, more and more high-income households might move out and the number of low-income households

\footnotetext{
${ }^{5}$ This finding is strongly echoed in Robertson et al (2008), who concluded that three neighbourhoods in Stirling, Scotland, had retained their relative social status over a period of centuries.
} 
in these particular areas will rise. The increasing mobility of residents causes faster turnover rates, which in turn can lead to vacancies, vandalism, pollution, low tenant participation and a further decline in the neighbourhood's reputation. These developments may result in technical decline, which can again lead to further mobility. Both social and technical decay may result in decreasing rent income (because of increasing mobility and the influx of more and more low-income households). At the same time, higher turnover rates, problems with tenants, increasing maintenance and, for example, landlords' attempts to ensure that the complex remains competitive, result in higher running costs (economic decline). A landlord may react to this unfavourable situation by relaxing the allocation rules for its properties, meaning that low-income households can enter the area more easily. Also, they can decide to invest less in maintenance. In both cases the spirals of decline continue to strengthen one another.

Superficially, this model appears very different from those of Bottoms et al., Taub et al., etc. Within it, however, one can detect the same sets of causal factors at work, namely, ecological (resident moves, condition of housing stock), institutional (housing management and maintenance practices) and sub-cultural (tenant behaviour). The model does not, however, explicitly cite any factors related to the intentional shaping and representing of a neighbourhood as a whole.

Still following a behavioural approach, Bottoms \& Wiles (2002: 632) have pointed to the role of peer influence or sub-culture, affecting daily routines, social activities, and thought processes. Such sub-cultural factors can either alleviate or exacerbate the changes in neighbourhood status resulting from factors of other types. Lupton (2004), for example, found that 'the illegal economy was normal, rational and well-established' in poverty neighbourhoods, involving drug dealing, buying stolen 
goods and shoplifting to order. However, such criminal activity can co-exist with strong social networks within the neighbourhood and does not necessarily signify low neighbourhood status, so the common assumption that crime and disorder is generally associated with neighbourhood decline is not correct (May et al., 2005). Rather, the relationship between the two is less direct and more complex. This suggests a need to move beyond behavioural approaches towards more sophisticated theoretical approaches that attempt to take account of such complexity.

\section{Structural approaches to neighbourhood change}

The behavioural approach is useful so far as it goes, therefore, but is limited in that it does not explain how factors of different types might interact so as to produce given kinds of neighbourhood change. Also, its conceptions of the different types of factors raise further questions about what, in turn, might be responsible for them - e.g. the causes of population migration, corporate decisions, offending cultures, etc. Ahlbrandt (1984: 123), therefore, on the basis of a random survey of 6,000 residents of Pittsburgh, Pennsylvania, suggested a new typology, in which neighbourhood change can be understood in three different ways: economically, in terms of household incomes or property values (e.g. gentrification or residualisation); socially, in terms of the character of its residential population (e.g. its mix of classes, ethnic groups, ages and household types); or with a focus on housing. Each of these ways of understanding conveys a greater breadth and depth of content than the typologies of either Bottoms et al. (1976) or Taub et al. (1984). Clearly, the relationships among the factors concerned are complex and vary from one neighbourhood to another. Taken together, they comprise the three dimensions of what Ahlbrandt (1984: 39) called the 'neighbourhood environment'. Despite the ecological language, therefore, this can be 
seen to represent a step towards a more structural approach to understanding neighbourhood change, in the sense of an approach that attempts to explain this change in terms of sets of relationships underlying manifest forms of behaviour. ${ }^{6}$

\section{1) Economic dimension}

Following a structural approach, Grigsby and colleagues (1987) looked more closely at the economic dimension of neighbourhood change. Specifically, they emphasised the importance of changes in socio-economic variables, causing households to change their behaviour in the housing market, resulting in changes in dwelling and neighbourhood characteristics. Grigsby et al particularly highlighted the concentration of poverty in a neighbourhood, associated with a critical mass of residents with behavioural problems, resulting in the unravelling of the neighbourhood's social fabric (see also Hope \& Shaw, 1988). Similarly, Lupton (2004) found that the pattern of decline, based on deindustrialisation and housing market change, was the same in all twelve of her case study areas, with the additional factor, in some areas, of a decline in public services, especially policing. Although significant reductions in unemployment had occurred in all twelve areas, a new 'culture of disposability', based on low skilled and temporary work, had taken root (Lupton, 2004: 201), so that the local economy remained unhealthy.

Both of these studies, along with many others with similar findings ${ }^{7}$, tend to suggest that residents in many (poorer) neighbourhoods are virtually powerless in the face of wider economic, institutional and political forces. Neither of them, however,

\footnotetext{
${ }^{6}$ In contrast, ecological and behavioural approaches focus only on the activities within a neighbourhood, and attempt to identify patterns to those activities.

${ }^{7}$ See, for example, Power (1997), on so-called 'mass' housing estates across Europe. For reviews of case studies of the effects of economic change on neighbourhoods and communities, see Crow and Allan (1994) and Day (2006).
} 
explicitly considers the issue of the absence of governance structures and processes in such neighbourhoods (which could shape and represent the neighbourhood as a whole) and therefore what difference the introduction of such neighbourhood governance might make. Neighbourhoods are seen as shaped by outside forces but they do not appear to enjoy any form of representation.

\section{2) Social dimension}

Studies emphasising the social dimension have used concepts of social trust, social fabric, social capital and collective efficacy. There would appear to be general agreement among them that these are crucial factors influencing neighbourhood change. We would argue that these concepts are important for highlighting the system of norms and sanctions that may exist in a neighbourhood, and so provide some understanding of how neighbourhoods are shaped, but they fall short of a focus on structures in and through which a neighbourhood can be represented, i.e. governance structures. .

Green and colleagues (2005), for example, looked at the sustainability of eight former coal-mining neighbourhoods in South Yorkshire, characterised by persistent labour market disadvantage, and concluded that there was a strong relationship between neighbourhood assets - particularly social assets of trust, safety and reciprocity - and neighbourhood well-being. Where residents mistrusted their neighbours, they were more likely to want to move away, to a 'better area' and, because of increased housing provision in the sub-region, they were often more able to do so. This led to a spiral of decline in those neighbourhoods where little regeneration investment had taken place. People moving out of the neighbourhoods tended to be younger, healthier and better qualified, so there was a need for initiatives 
(e.g. affordable housing provision) that would attract similar people back into the areas. Such initiatives, however, are unable to guarantee the sustainability of the neighbourhoods concerned, as the newcomers are unlikely to mix with the existing residents, even within the same housing development. This study therefore shows the importance of social trust within a neighbourhood (mediated through the housing market) for arresting its decline when labour market conditions are unfavourable. The question of structures for shaping and representation, however, is addressed only indirectly, in connection with policy going beyond the neighbourhood on, for example, health and regeneration. The concept of social trust is not placed within a context of developing governance on a neighbourhood scale.

Similarly, Temkin \& Rohe (1996) stress the importance of the social fabric for encouraging or resisting neighbourhood change, where 'social fabric' is understood as a combination of 'intimate bonds' (of kinship and strong friendship) and 'neighbouring' developed through borrowing, visiting and helping activities (Ahlbrandt, 1984: 108). Although they give priority to economic and social forces outside the neighbourhood (e.g. loss of manufacturing jobs or an influx of ethnic minorities), they show that it is essential to consider how these forces are actually played out within each neighbourhood and, in particular, how local residents and organisations interpret and respond to these forces. For example, residents may decide to move or to organise instead, while institutions may try to resist the change, e.g. through increasing public investment (Temkin \& Rohe, 1996: 166). Clearly, neighbourhoods with a strong social fabric are better able to resist changes than areas with a weak social fabric. In general, the concept of social fabric seems very similar to that of social capital, especially bonding social capital. Arguably, therefore, social 
fabric could form the foundation on which neighbourhood governance can be built, but this possibility remains undeveloped.

Writers using the concept of social capital have noted how the attenuation and decline of social relations within a neighbourhood can reduce its liveability or the quality of life of its residents (for a comprehensive review, see Halpern, 2005). Also, Sampson et al. (1997) argue that high crime neighbourhoods lack the kinds of social capital that would allow them to define collective goals and then organise effectively to achieve them, and they call this a lack of collective efficacy. In the context of a neighbourhood, they define collective efficacy as 'the linkage of mutual trust and the willingness to intervene for the common good' (Sampson et al., 1997: 919). Their research shows that variations in violent crime rates among Chicago neighbourhoods can be partially explained by the relative possession of the capacity for collective efficacy (Sampson et al., 1997: 923). Clearly again, willingness to intervene for the common good looks like a necessary condition for effective neighbourhood governance - indeed, it could be argued that willingness to act for the good of a neighbourhood is an indicator of capacity to shape and represent that neighbourhood. This idea, however, is not developed here. ${ }^{8}$

\section{3) Housing dimension}

\footnotetext{
${ }^{8}$ One problem with the collective efficacy approach is that it assumes that the community is basically composed of 'good citizens'. As Bottoms \& Wiles (2002: 644) point out, however, some criminal gangs can be collectively efficacious but the results are not necessarily desirable for the community as a whole. For example, in Walklate \& Evans (1999), the Salford Firm in Oldtown policed local criminal incidents by giving culprits a 'smacking' (physical chastisement) and by intimidating 'grasses' (people who complained to the police about the Firm's actions). More generally, differences and divisions within communities can mean that a high level of population turnover (working against collective efficacy) can co-exist with a stable community of residents (working in favour of collective efficacy) (Hancock, 2001: 188). Case studies of different housing estates suggest that such a situation may not be uncommon (Reynolds, 1986; Page, 2000). Such empirical considerations suggest that theories of social capital and collective efficacy, while potentially very useful in drawing attention to the agency dimension of neighbourhood change, may, like previous ecological and behavioural concepts, suffer from a certain circularity and lack of explanatory 'bite' (e.g. neighbourhood improvement is caused by collective efficacy, while collective efficacy is whatever causes neighbourhood improvement).
} 
It is clear that housing figures prominently in the literature on neighbourhood change. The US studies tend to focus on the private housing market while the European studies have mainly looked at social rented housing. In spite of this difference, the findings are similar, in that the rules by which the tenure operates tend to mediate the ecological facts, though in different ways. The private market uses the price mechanism to determine concentrations of poorer households in declining neighbourhoods. According to followers of the neo-weberian approach, for example, there is competition between households to gain access to desirable dwellings ('housing classes') (Rex \& Moore, 1967). Whether a household has this access or not is highly influenced by its resources, for example income (see Van Kempen \& Özüekren, 1998, for an overview of these resources). The social rented sector, on the other hand, employs bureaucratic or (more recently) 'choice-based' allocation to achieve almost similar results.

An important consideration here is that wider economic inequality combined with government policy that is oriented to market provision can result in a process of residualisation. This refers to the narrowing social profile of the social rented sector. Residualisation can be observed in several Western European countries, but the developments seem to be more dramatic in some countries (e.g. Britain and Germany) than in others (e.g. Denmark and the Netherlands) (see Forrest \& Murie, 1983; Forrest \& Murie, 1988; Meusen \& Van Kempen, 1994; Harloe, 1995). Basically, the residualisation concept focuses on housing sectors, but can easily be applied to the neighbourhood level. Then residualisation refers to the increasing concentration of lower-income households in neighbourhoods with less valued attributes. However, the concept explains only why certain neighbourhoods may experience a decline in the capacity to shape and represent themselves, and does not focus on the (lack of) 
capacity itself, i.e. it does not give explicit attention to the issue of neighbourhood governance.

One important scholar here is Power (1997), who emphasises the interaction between the physical design and layout of a neighbourhood and its social (and economic) conditions. She sees neighbourhood decline primarily in terms of a loss of territorial control, so that the residualisation that is associated with that decline is explicitly linked to the lack of resident capacity to shape the neighbourhood. For Power, territorial control has to be regained through the introduction of new forms of neighbourhood management, with the support of the residents themselves, and this could be seen as a possible form of neighbourhood co-governance. However, it seems to ignore or even disparage the role of existing social networks within (declining) neighbourhoods and its conception of neighbourhood management does not quite equate with neighbourhood governance as understood in this paper. It is a structural explanation because it takes account of the social pressures arising from economic decline but then it offers merely managerial solutions through what it calls a 'local rescue focus' (Power, 1997: 379), which involves interventions to restore neighbourhood stability and strong social control (:386-8). Its focus is on shaping neighbourhoods through decisive collective action but not on developing the representation of those neighbourhoods. The role of governance is recognised only in relation to 'central institutions' (Power, 1997: 392) - there is no conception of representation specifically at the level of a neighbourhood. It talks about 'creating a sense of control at ground level' (Power, 1997: 398) but, far from being control by the community, this appears to be a form of control of the community, in which the community itself is actively involved. 
Later research following a similar approach has found that neighbourhood regeneration depends not only on the implementation of effective neighbourhood management but also on sustained capital investment over long periods, led by government and its partners, with residents playing a key role. In addition, other changes in the wider economy and society, particularly rising employment, a buoyant housing market, falling crime and rising educational achievement are influential (Tunstall \& Coulter, 2006).

\section{Evaluation of structural approaches to neighbourhood change}

Taken together, what the 'structural' studies show is that housing markets work by institutionally mediating ecological facts produced by wider socio-economic forces, resulting in sub-cultural change. The key line of causation runs from the performance of the economy and the state at a macro level to the neighbourhood environment, but this is mediated primarily through housing markets, which are themselves partially determined by the political economy and partially determine the nature and quality of the neighbourhood environment. However, the housing market is not the only institution that mediates in this way - practically any public, private or voluntary organisation operating at a meso level in the neighbourhood environment can perform a similar function (e.g. schools, businesses, local authorities, police forces, health authorities, charities). Moreover, within that environment, social relations not only can exert a reciprocal effect on the housing market and other institutions but also can counteract the effects of the political economy (whether these effects be negative, in terms of neighbourhood decline, or positive, in terms of neighbourhood rise) - cf. the discussion of Temkin \& Rohe (1996) above. 
Human ecology and behavioural approaches are useful for making sense of this complexity, but they have their limitations. This is partly because the neighbourhood environment as a whole, as well as each element within that environment, both affects and is affected by macro-economic and political processes, and also affects and is affected by meso-level institutions such as the housing market. In comparison, a structural approach may prove to be more illuminating, with neighbourhood change being explained in terms of complex interactions of social, economic and spatial factors. Structural explanations vary, however, according to which factors are selected and how they are seen to combine and interact. Consequently, it is possible to have competing explanations, with no clear way of deciding between them.

A common problem with structural approaches is that they tend to subordinate agency to structure, that is, they identify factors that can act as causes of neighbourhood change, but their accounts of the capacity of action for change are less well developed, e.g. they do not sufficiently explore the potential for social capital development within the neighbourhood or else they do not focus on how that social capital might shape the neighbourhood and form a foundation for its representation in other words, they do not give sufficient consideration to issues of neighbourhood governance. Ahlbrandt's concept of the neighbourhood environment, for example, does not include factors concerned with the intentional shaping and representation of neighbourhoods. Other researchers following a structural approach tend to focus on one or more of Ahlbrandt's three factor types, such as economic (Grigsby et al., 1987; Lupton, 2004), social (Sampson et al., 1997; Green et al., 2005), or spatial (Power, 1997; Tunstall \& Coulter, 2006). Overall, a key factor that structural approaches have not integrated into their theory is that of the capacity of neighbourhood residents (on 
their own or in co-operation with other stakeholders) to shape the neighbourhood and represent it to others.

\section{Neighbourhood change and neighbourhood governance}

The question of the nature and extent of residents' participation in neighbourhood governance is crucial because this determines the dominant mode of governance in a neighbourhood. A feature of hierarchical governance, for example, is that, if residents participate in governance at all, it is only tokenistic, in that they have no influence on the key decisions that are taken. For self-governance, in contrast, residents make all the key decisions affecting their neighbourhood (or specific attributes of that neighbourhood). In many cases where some form of governance institution exists in a neighbourhood, however, we have examples of co-governance, where governmental bodies work with residents' groups in a variety of forums and partnerships.

Research (particularly by Ahlbrandt) suggests that residents' attachment to their neighbourhood (irrespective of how satisfied or dissatisfied they may be with it) is the most important factor associated with their participation in neighbourhood life generally, and in neighbourhood governance in particular (see, most recently, Livingston et al, 2008). In particular it seems that more people are likely to participate, and to participate more, if their participation is valued (and indeed invited) and if they can be confident of the collective as well as individual benefits that their participation will bring (Simmons \& Birchall, 2005). These findings suggest that the structural approach to understanding neighbourhood change needs to be extended to cover the effects of policies relating to resident participation, i.e. focusing not just on the collective capacity of residents to achieve change but also on the capacity and willingness of the political system to respond to residents' needs and aspirations, and 
specifically on the absence or presence of civic infrastructure that will facilitate and support resident-led neighbourhood improvement. In short, understanding neighbourhood change requires attention to the capacity of the system to develop neighbourhood governance and the orientation of that system towards different modes of governance (hierarchical, self- and co-governance).

In a number of countries, it has been shown that, when formal opportunities for participation are created (mainly by government) for neighbourhood residents, few actually participate (for the UK, see Getimis et al, 2006 and Skidmore et al, 2006; for the Netherlands, Spain and Hungary, see Van Beckhoven et al, forthcoming; for Europe generally, see Bull and Jones, 2006, and Keil, 2006). When instruments to facilitate participation are available, neighbourhood characteristics have an enormous influence on their use - for example, residents' associations with weak structures, lack of such associations, or uncooperative associations can form a barrier to the development of local participation. On the other hand, when formal instruments are lacking, a strong association structure or a high level of neighbourhood social cohesion can lead residents to develop their own participation instruments. However: 'The point is that to date relatively little has been done to put mechanisms in place that ensure that all neighbourhoods in a city have the opportunity to develop and articulate collective neighbourhood views and to ensure these can be brought together at a city-wide level other than through traditional local electoral mechanisms, which are increasingly viewed as inadequate' (Atkinson, 2007: 72). Neighbourhood governance as understood in this paper therefore remains a largely untapped potential. $^{9}$

\footnotetext{
${ }^{9} \mathrm{We}$ are of course far from being the first to point out the lack of governance structures and processes within neighbourhoods and the significance of this lack for community development. For example, Taylor $(1995,2000,2003,2007)$ has long argued that such institutions need to be in place if disadvantaged neighbourhoods are to be turned around. What has so far been missing from Taylor's
} 
Neighbourhood governance, or rather the lack of it, could also be responsible for many of the problems found in poorer neighbourhoods in particular. This is because the absence of legitimate democratic institutions and processes of conflict resolution within the neighbourhood can lead to attempts by certain groups to gain and maintain control over what they see as their territory or 'turf' by physical force and intimidation. This in turn can lead to bitter divisions, conflicts and disorder, which are found in many of these neighbourhoods (and commented on by, for example, Reynolds, 1986; Walklate \& Evans, 1999; Page, 2000; Hancock, 2001; Bottoms \& Wiles, 2002).

The effects of different modes of governance on neighbourhood change have not yet been studied in any detail. One way in which co-governance could work, however, for example as a means to reverse neighbourhood decline, is where a neighbourhood democratic authority (such as a commune in France) acts in partnership with other organisations responsible for (aspects of) the neighbourhood environment. Since the partnership has to be reasonably equal in order to ensure that the needs of the neighbourhood are fully recognised, it is necessary for neighbourhood governance to be scaled up to higher levels of decision-making, typically at municipal level in the first instance, and for higher levels of political governance to be scaled down to the neighbourhood level, or as near to it as is practicable. This could be achieved through appropriate forms of federation and clustering on the one hand, and strategically planned devolution on the other. The whole process, of simultaneously scaling up and scaling down political governance, is required to ensure that the empowerment of poorer neighbourhoods is real and

analysis, however, is a clear identification of what kinds of bodies might count as neighbourhood governance ones, i.e. as both shapers of neighbourhood place and representers of the neighbourhood as a whole. In general, the literature on community participation is strong on normative questions but lacks clear focus on the capacity for resident participation in neighbourhood governance. 
enduring. Such co-governance between residents and the state would ensure a unity of resident 'ownership' and two-way accountability (of the state to the residents and of the residents to the state) (see Somerville, 2009).

In the UK, for example, the New Labour government has been encouraging neighbourhood governance, particularly through the New Deal for Communities and Neighbourhood Management Pathfinders, and is now progressing this agenda further (see, for example, ODPM, 2005; CLG, 2006; CLG, 2008). ${ }^{10}$ A variety of neighbourhood governance institutions have been established, and the agenda contains important potential for co-governance (see, for example, Somerville \& Haines, 2008). As Smith et al. (2007) point out, however, the government has no clear conception of neighbourhood or of neighbourhood governance. As yet, not only in the UK but also in many other countries, very few initiatives have managed to achieve both a high degree of resident participation and effective representation of residents in neighbourhood decision-making (see, for example, Barnes et al., 2007; Atkinson \& Carmichael, 2007). ${ }^{11}$

One thing that has become increasingly clear, however, is that, although it can and does play a key role, housing governance on its own is incapable of reversing neighbourhood decline - all the major regeneration successes in England such as The Eldonians, Castle Vale, Royds, Coin Street, and so on, have worked across a number of fronts, particularly in creating jobs, building assets, improving health and social care, working with young people, and exercising political leadership on at least a city-

\footnotetext{
${ }^{10}$ Much of this, of course, is not neighbourhood governance as we have defined it but neighbourhood management or else it is little more than national governance implanted into selected neighbourhoods. A discussion of this point, however, would take us beyond the scope of this article.

${ }^{11}$ The deeper reasons for this badly need to be explored but instead attention now seems to be in the process of shifting to 'citizen-centred governance' (Barnes et al, 2008 - see also, Lowndes and Sullivan, 2008). This sees governance misleadingly in terms of delivering public services rather than shaping and representing places or communities, and risks blurring the differences between modes of governance as defined by Kooiman. Politics seem conspicuous by their absence. This is not to deny that the governance of public services (particularly housing) is very important for neighbourhood change but it should not be confused with the governance of neighbourhoods themselves.
} 
wide, city-region and regional scale. In all these cases, community-based housing associations and/or cooperatives have been an integral part of the success story but it would be misleading to say that the regeneration has been housing-led.

\section{Conclusion}

The variety of neighbourhood governance is increasing, and this can be interpreted either as a problem (e.g. of 'fragmentation') or as a welcome sign of diversity. Measures to give residents greater powers and responsibilities can be seen as genuinely empowering or as increasing the burdens of those who are already oppressed and over-laden. If the aim is to do the former, then the argument in this paper suggests that instruments enabling residents to participate need to be developed on the neighbourhood scale, taking into account the extent of social cohesion, the composition of the neighbourhood population, the structure of any residents' associations, and the extent of the residents' trust in national or local policy (see also Van Beckhoven et al., 2005) - joining together the links in what Simmons \& Birchall (2005: 277-8) call the 'participation chain'.

In addition, an integrated approach is essential for successful policy outcomes. The tendency to integrate policies is quite strong in European countries, especially in area-based policies (policies, for example focused on a single neighbourhood). The advantage of integrated efforts is clear on this spatial level: combinations of problems can be attacked from different angles. However, only when all parties (e.g. local government, housing associations, shop owners, inhabitants, private developers) can come to an agreement about the content of the policy, is it possible for success to be generated (see e.g. Van Kempen \& Van Beckhoven, 2006). This is not to say that universal consensus is required for successful neighbourhood regeneration but only 
that there is a need for some kind of decision-making forum at neighbourhood level where disagreements can be openly debated and conflicts resolved as far as possible.

Neighbourhood change is caused not only by outside forces, but also by all kinds of processes that are more or less internal to the neighbourhood. These processes relate not only to housing but also to employment, education, transport, health, crime, public amenities, leisure and recreation, shops, relations within households, etc. Neighbourhood governance is one means by which such processes can be integrated. Without appropriate neighbourhood governance institutions, issues of accountability and legitimacy tend to be blurred or confused, with accountability upwards to authorities and agencies outside the neighbourhood tending to contradict and over-ride accountability to those living and working in the neighbourhood. Neighbourhood improvements are at risk of being reversed as traditional vertical lines of accountability re-assert themselves, and resources devoted to such improvement will tend to be captured by organisations that are not neighbourhood-based. Even where a neighbourhood has seemingly declined past the point of no return, it is arguable that its residents should have the main say in deciding its future, and this can only be safeguarded where appropriate neighbourhood governance structures are in place. The nature of such structures should, so far as possible, be decided through open negotiations with the totality of residents in each neighbourhood, on the basis of which forms of representation that are acceptable to all residents are most likely to emerge.

\section{References}

Aalbers, M., Van Beckhoven, E., Van Kempen, R., Musterd, S. \& Ostendorf, W. (2003) Large Housing Estates in the Netherlands: Overview of Developments in 
Amsterdam and Utrecht (Utrecht: Faculteit Geowetenschappen Universiteit Utrecht).

Ahlbrandt, R. \& Brophy, P. (1975) Neighbourhood Revitalization (Lexington, D.C.: Heath and Company).

Ahlbrandt, R.S. \& Cunningham, J.V. (1979) A New Public Policy for Neighbourhood Preservation (New York, Praeger).

Ahlbrandt, R. S. (1984) Neighbourhoods, People and Community (London: Plenum Press).

Atkinson, R. (2007) Under construction - the city-region and the neighbourhood: new actors in a system of multi-level governance? In I. Smith, E. Lepine \& M. Taylor (Eds) Disadvantaged By Where You Live? (Bristol: The Policy Press), pp. 65-82.

Atkinson, R. \& Carmichael, L. (2007) Neighbourhood as a new focus for action in the urban policies of West European states, in: I. Smith, E. Lepine \& M. Taylor (Eds) Disadvantaged By Where You Live? (Bristol: The Policy Press), pp. 43-63.

Bailey, N., Barker, A. \& MacDonald. K. (1995), Partnership Agencies in British Urban Policy (UCC Press, London).

Baldwin, J. \& Bottoms, A. E. (1976) The Urban Criminal (London: Tavistock).

Barnes, M., Newman, J. \& Sullivan, H. (2007) Power, Participation and Political Renewal: Case studies in public participation (Bristol: The Policy Press).

Barnes, M., Skelcher, C., Beirens, H., Dalziel, R., Jeffares, S. and Wilson, L. (2008) Designing Citizen-Centred Governance (York: Joseph Rowntree Foundation).

Birch, D. (1971) Towards a stage theory of urban growth, Journal of the American Institute of Planners, pp. 78-87.

Bottoms, A. E., Claytor, A. \& Wiles, P. (1992) Housing markets and residential 
crime careers: a case study from Sheffield, in: D.J. Evans, N.R. Fyfe \& D.T. Herbert (Eds) Crime, Policing and Place: Essays in Environmental

Criminology (London: Routledge).

Bottoms, A. E., Mawby, R.I. \& Xanthos, P. (1989) A tale of two estates, in:

D. Downes (Ed) Crime and the City: Essays in memory of John Barron Mays (Basingstoke: Macmillan).

Bottoms, A.E. \& Wiles, P. (2002) Environmental criminology, in: M. Maguire, R. Morgan \& R. Reiner (Eds) The Oxford Handbook of Criminology. $3^{\text {rd }}$ ed. (Oxford: Oxford University Press).

Bull, A. and Jones, B. (2006) Governance and social capital in urban regeneration, Urban Studies, 43 (4), pp. 767-786.

Burgess, E.W. (1925) The growth of the city: an introduction to a research project, in: R.E. Park, E.W. Burgess \& R.D. McKenzie (Eds) The City (Chicago/London: University of Chicago Press).

Clarke, C. \& Newman, J. (1997), The Managerial State, Power, Politics and Ideology in the Remaking of Social Welfare (Sage, London).

Cole, I. \& Furbey, R. (1994) The Eclipse of Council Housing (London: Routledge).

Cole, I. \& Nevin, B. (2004) The Road to Renewal (York: Joseph Rowntree Foundation/Sheffield Hallam University).

Communities and Local Government (CLG) (2006) Strong and Prosperous Communities: The Local Government White Paper. Available at: www.communities.gov.uk.

Communities and Local Government (CLG) (2008) Communities in Control: Real people, real power (London: CLG). 
Crow, G. and Allan, G. (1994) Community Life: An introduction to local social relations (Hemel Hempstead: Harvester Wheatsheaf).

Day, G. (2006) Community and Everyday Life (London: Routledge).

Dekker K. \& Van Kempen, R. (2004), Urban governance within the Big Cities Policy: ideals and practice in Den Haag, the Netherlands, Cities 21 (2), pp. 109-117.

Elander, I. (2002), Partnership and urban governance, International Social Science Journal, 172, pp. 191-204.

Evans, K. (1998) Community safety in high crime neighbourhoods: a view from the street, in: A. Marlow \& J. Pitts (Eds) Planning Safer Communities (Lyme Regis: Russell House Publishing).

Firey, W. (1947) Land Use in Central Boston (Cambridge, Massachusetts: Harvard University Press).

Getimis, P., Heinelt, H. and Sweeting, D. (eds) (2006) Leadership and Participation: Searching for sustainability in European cities (London: Routledge).

Green, G., Grimsley, M. \& Stafford, B. (2005) The Dynamics of Neighbourhood Sustainability (York: Joseph Rowntree Foundation).

Grigsby, W., Baratz, M., Galster, G. \& Maclennan, D. (1987) The dynamics of neighbourhood change and decline, Progress in Planning, 28, pp. 1-76.

Hall, P. (1997) Regeneration policies for peripheral housing estates: inward- and outward-looking approaches, Urban Studies, 34 (5), pp. 873-890.

Hall, S., Lee, P., Murie, A., Rowlands, R. \& Sankey, S. (2003) Large Housing Estates in United Kingdom: Overview of Developments in London and Birmingham (Utrecht: Faculteit Geowetenschappen Universiteit Utrecht).

Halpern, D. (2005) Social Capital (Cambridge: Polity Press).

Hancock, L. (2001) Community, Crime and Disorder: Safety and Regeneration in 
Urban Neighbourhoods (Basingstoke: Palgrave).

Hilder, P. (2006) Local Democracy and Neighbourhood Governance (London: The Young Foundation).

Hirst, P. (2000) Democracy and governance, in: J. Pierre (Ed) Debating Governance (Oxford: OUP).

Hope, T. \& Shaw, M. (1988) Community approaches to reducing crime, in: T. Hope \& M. Shaw (Eds) Communities and Crime Reduction (London: HMSO).

Hoyt, H. (1939) The Structure and Growth of Residential Neighbourhoods in American Cities (Washington, DC: Federal Housing Administration).

Imrie, R. \& Raco, M. (1999), How new is the new local governance? Lessons from the United Kingdom, Transactions of the Institute of British Geographers, New Series, 24 (1), pp. 45-63.

Kearns, A. \& Parkinson, M. (2001) The significance of neighbourhood, Urban Studies, 38 (12), pp. 2103-2110.

Keil, A. (2006) New urban governance processes on the level of neighbourhoods, European Planning Studies, 14 (3), pp. 335-364.

Kennett, P. \& Forrest, R. (2006) The neighbourhood in a European context, Urban Studies, 43 (4), pp. 713-718.

Kooiman. J. (1993), Modern Governance, New Government-Society Interactions (London: Sage).

Kooiman, J. (2005) Governing as Governance (London: Sage).

Le Galès, P. (1998) Regulations and governance in European cities, International Journal of Urban and Regional Research, 20 (3), pp. 482-507.

Lipsky, M. (1980) Street-Level Bureaucracy: Dilemmas of the individual in public services (New York: Russell Sage). 
Livingston, M., Bailey, N. and Kearns, A. (2008) People's Attachment to Place - The influence of neighbourhood deprivation (York: Joseph Rowntree Foundation).

Lupton, R. (2004) Poverty Street: The dynamics of neighbourhood decline and renewal (Bristol: The Policy Press).

May, T., Duffy, M., Few, B. \& Hough, M. (2005) Understanding Drug Selling in Communities: Insider or outsider trading? (York: Joseph Rowntree Foundation).

Marcuse, P. \& Kempen, R. van (2000), Conclusion: a changed spatial order. In: P. Marcuse \& R. van Kempen (eds.), Globalizing Cities: A New Spatial Order?, pp. 249-275 (Oxford: Blackwell).

Megbolugbe, I.F., Hoek-Smit, M.C. and Linnenman, P.D. (1996), Understanding neighbourhood dynamics: A review of the contributions of William G. Grigsby, Urban Studies, 33, pp. 1779-1795.

Molotch, H. (1976) The city as growth machine: toward a political economy of place, American Journal of Sociology, 82, pp. 309-330.

Murie, A., Knorr-Siedow, T. \& Van Kempen, R. (2003) Large Housing Estates in Europe: General Developments and Theoretical Backgrounds (Utrecht: Utrecht University).

Office of the Deputy Prime Minister (ODPM) (2005) Citizen Engagement and Public Services: Why Neighbourhoods Matter (London: ODPM). Available at: www.odpm.gov.uk/stellent/groups/odpm_localgov/documents/page/odpm_locgov 03488 $\underline{0 . p d f}$

Page, D. (2000) Communities in the Balance? The Reality of Social Exclusion on Housing Estates (York: Joseph Rowntree Foundation).

Pahl, R. (1975) Whose City? (Harmondsworth: Penguin).

Pahl, R. (1977) Managers, technical experts and the state, in: M. Harloe (Ed) Captive 
Cities (London: Wiley).

Power, A. (1997) Estates on the Edge: The social consequences of mass housing in northern Europe (London: Macmillan).

Prak, N.L. \& Priemus, H. (1986) A model for the analysis of the decline of postwar housing, International Journal of Urban and Regional Research, 10, pp. 1-7.

Prime Minister's Strategy Unit and ODPM (2005) Improving the Prospects of People Living in Areas of Multiple Deprivation in England (London: Cabinet Office).

Purdue, D. (2005) Community leadership cycles and the consolidation of neighbourhood coalitions in the new local governance, Public Management Review, 7 (2), pp. 247-66.

Reiss, A. J. (1986) Why are communities important in understanding crime? In: A.J. Reiss \& M. Tonry (Eds) Communities and Crime: Crime and Justice, A Review of Research, 8 (Chicago: University of Chicago Press).

Rex, J. \& Moore R. (1967) Race, Community, and Conflict (London: Oxford University Press).

Reynolds, F. (1986) The Problem Housing Estate (Aldershot: Gower).

Rhodes, R. (1996), The new governance: governing without government, Political Studies, 44 (4), pp. 652-667.

Rhodes, R. (1997) Understanding Governance, Policy Networks, Governance, Reflexivity and Accountability (Open University Press, Buckingham).

Robinson, F., Shaw, K. \& Davidson, G. (2005) 'On the side of the angels': community involvement in the governance of neighbourhood renewal, Local Economy, 20 (1), pp.13-26.

Sampson, R.J., Raudenbush, S.W. \& Earles, F. (1997) Neighborhoods and violent crime: a multilevel study of collective efficacy, Science, 277, pp. 918-924. 
Schuerman, L. \& Kobrin, S. (1986) Community careers in crime, in: A.J. Reiss \& M. Tonry (Eds) Communities and Crime, 8 (Chicago: University of Chicago Press).

Simmons, R. \& Birchall, J. (2005) A joined-up approach to user participation in public services: strengthening the "participation chain", Social Policy \& Administration, 39 (3), pp. 260-283.

Skidmore, P., Bound, K. and Lownsbrough, H. (2006) Community Participation: Who Benefits? York: Joseph Rowntree Foundation.

Skifter Andersen, H. (2002), Excluded places: the interaction between segregation, urban decay and deprived neighbourhoods, Housing, Theory and Society, 19, pp. 153-169.

Skogan, W.G. (1990) Disorder and Decline: Crime and the Spiral of Decay in American Neighborhoods (New York: The Free Press).

Smith, I., Lepine, E. \& Taylor, M. (Eds) (2007) Disadvantaged By Where You Live? Neighbourhood governance in contemporary urban policy (Bristol: The Policy Press).

Somerville, P. (2009, forthcoming) Neighbourhood multiscalarity and governance, International Journal of Urban and Regional Research,

Somerville, P. \& Haines, N. (2008) Prospects for local co-governance, Local Government Studies, 34 (1), pp. 61-79.

Stoker, G. (2004) Transforming Local Governance (Basingstoke: Palgrave Macmillan).

Stone, C. (1989), Regime Politics: Governing Atlanta, 1946-1988 (University Press of Kansas, Lawrence). 
Sullivan, H. (2001) Modernisation, democratisation and community governance, Local Government Studies, 27 (3), pp. 1-24.

Sullivan, H. (2002) Modernisation, neighbourhood management and social inclusion, Public Management Review, 4 (4), pp. 505-528.

Taub, R.P., Taylor, D.G. \& Dunham, J.D. (1984) Paths of Neighborhood Change: Race and Crime in Urban America (Chicago: University of Chicago Press).

Taylor, M. (1995) Unleashing the Potential (York: Joseph Rowntree Foundation).

Taylor, M. (2000) Top Down Meets Bottom Up: Neighbourhood management (York: Joseph Rowntree Foundation).

Taylor, M. (2003) Public Policy in the Community (Basingstoke: Palgrave Macmillan).

Taylor, M. (2007) Community participation in the real world: opportunities and pitfalls in new governance spaces, Urban Studies, 44 (2), pp. 291-317.

Taylor, R.B. (2001) Breaking Away from Broken Windows: Baltimore neighborhoods and the nationwide fight against crime, grime and fear of decline (Boulder, Col: Westview).

Temkin, K. and Rohe, W.M. (1996) Neighbourhood change and urban policy, Journal of Planning Education and Research, 15 (3), pp. 159-170.

Temkin, K. and Rohe, W.M. (1998), Social capital and neighbourhood stability: an empirical investigation, Housing Policy Debate, 9, pp. 61-88.

Tunstall, R. \& Coulter, A. (2006) Twenty-Five Years on Twenty Estates: Turning the tide? (Bristol: The Policy Press/Joseph Rowntree Foundation).

Turkington, R., Van Kempen, R. \& Wassenberg, F. (2004) High-rise Housing in Europe. Current Trends and Future Prospects (Delft: DUP Science). 
Van Beckhoven, E., Van Boxmeer, B. \& Garcia Ferrando, L. (2005) Local participation in Spain and the Netherlands, in: R. Van Kempen, S. Hall, I. Tosics \& K. Dekker (Eds) Restructuring Large Housing Estates in Europe (Bristol: The Policy Press).

Van Beckhoven, E. \& Van Kempen, R. (2006) Towards more social cohesion in large post-WWII housing estates? A case study in Utrecht, the Netherlands, Housing Studies, 21 (4), pp. 477-500.

Van Beckhoven, E., Van Boxmeer, B. \& Szemző, H. (forthcoming) Local participation in European large housing estates.

Van Kempen, R. (2002) The academic formulations: explanations for the partitioned city, in: P. Marcuse and R. van Kempen (Eds) Of States and Cities: The partitioning of urban space (Oxford: Oxford University Press).

Van Kempen, R. \& Özüekren, A.Ş. (1998) Ethnic segregation in cities: new forms and explanations in a dynamic world, Urban Studies, 35 (10), pp. 1631-1656.

Van Kempen, R. \& Van Beckhoven, E. (2006) Urban governance and integrated policies, in: R. Van Kempen, A. Murie, T. Knorr-Siedow \& I. Tosics (Eds) Regenerating Large Housing Estates in Europe: A guide to better practice (Utrecht: Faculty of Geosciences, Utrecht University).

Varady, D.P. (1986) Neighborhood Upgrading, A Realistic Assessment (Albany: State University of New York Press).

Walklate, S. \& Evans, K. (1999) Zero Tolerance or Community Tolerance? (Aldershot: Ashgate).

White, G., Dickinson, S., Miles, N., Richardson, L., Russell, H. \& Taylor, M. (2006) Exemplars of Neighbourhood Governance (London: Department of Communities and Local Government). 
Whitehead, M. (2003) Love thy neighbour - rethinking the politics of scale and Walsall's struggle for neighbourhood democracy, Environment and Planning A 35, pp. 207-230. 